Table 1. Equivalent Conductance of Sodicm Stannate Solutioxs at Zero Time

\begin{tabular}{|c|c|c|c|c|c|}
\hline $\begin{array}{l}\text { Molar concentration sodium stannate } \\
\text { Equivalent conductance }\left(\mathrm{ohm}^{-1} \mathrm{~cm} .^{2}\right) \\
\text { Molar concentration sodium stannate } \\
\text { Equivalent conductance }(\mathrm{ohm}-1 \text { cm. } \\
\text { Molar concentration sodium stannate } \\
\text { Equivalent conductance (ohm-1 } \mathrm{cm}^{-1} \text { ) }\end{array}$ & $\begin{array}{c}0 \\
111 \cdot 8 \\
5 \cdot 485 \times 10^{-4} \\
105 \cdot 0 \\
4 \cdot 896 \times 10^{-3} \\
92 \cdot 7\end{array}$ & $\begin{array}{l}1 \cdot 035 \times 10^{-4} \\
110 \cdot 7 \\
7 \cdot 018 \times 10^{-4} \\
103 \cdot 1 \\
5 \cdot 216 \times 10^{-8} \\
91 \cdot 4\end{array}$ & $\begin{array}{c}1 \cdot 179 \times 10^{-4} \\
109 \cdot 0 \\
1 \cdot 051 \times 10^{-3} \\
100 \cdot 3 \\
6 \cdot 993 \times 10^{-3} \\
91 \cdot 1\end{array}$ & $\begin{array}{l}1 \cdot 735 \times 10^{-4} \\
107 \cdot 0 \\
1 \cdot 527 \times 10^{-3} \\
99 \cdot 5 \\
7 \cdot 564 \times 10^{-3} \\
88 \cdot 6\end{array}$ & $\begin{array}{c}2 \cdot 639 \times 10^{-4} \\
106 \cdot 4 \\
3 \cdot 553 \times 10^{-3} \\
93 \cdot 9 \\
1 \cdot 246 \times 10^{-2} \\
85 \cdot 6\end{array}$ \\
\hline
\end{tabular}

The equivalent conductivity at infinite dilution, $111 \cdot 8$, was obtained from a Kohlrausch plot; on correction for the effect of hydrolysis has been made. The difference between this value and the value of 156 obtained by Bellucci and Parravano ${ }^{5}$ for potassium stannate is greater than the theoretical one. Bellucci and Parravano, however, only noted an increase in conductivity with time in their most concentrated solution, so it is possible that their potassium stannate was impure.

The increase in conductivity with time and the final attainment of a limiting value shows that the species initially present are reacting at a measurable rate. By means of $p \mathrm{H}$ measurements it has been shown that for approximately the first 70 per cent of the reaction the increase in specific conductivity is a direct measure of the increase in hydroxyl ion concentration of the solution. The rate of production of hydroxyl ions is a first or pseudo-first order reaction with a rate constant of $5 \cdot 3 \times 10^{-2} \mathrm{hr}^{-1}$. The hydrolysis of sodium stannate is thus seen to occur in at least two stages: first, a fast reaction, typified by the immediate alkaline reaction of a freshly prepared stannate solution, and, secondly, by a slow first or pseudo-first order formation of more hydroxyl ions. Unfortunately, there are insufficient data available at present to make a more detailed mechanistic analysis of these reactions; but in view of the fact that both silicates and germanates form polynuclear hydrolysis products it seems likely that a similar explanation would apply in the case of stannate solutions.

I wish to thank the Superintendent of the Admiralty Materials Laboratory for permission to publish this work.

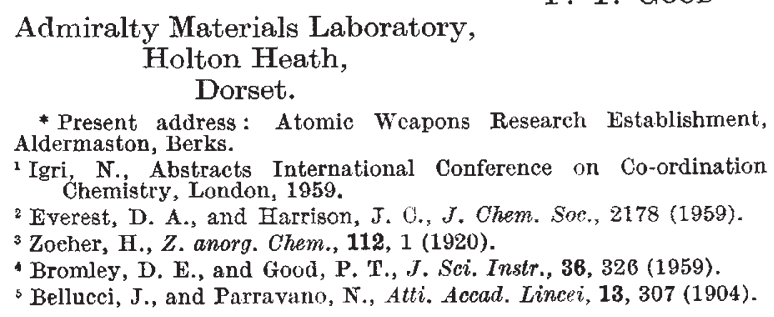

* Present address: Atomic Wcapons Research Establishment, Aldermaston, Berks.

${ }^{1}$ Igri, N., Abstracts International Conference on Co-ordination Chemistry, London, 1859.

2 Everest, D. A., and Harrison, J. O., J. Chem. Soc, 2178 (1959).

${ }^{3}$ Zoeher, H., Z. anorg. Chem., 112, 1 (1920).

- Bromley, D. E., and Good, P. T., J. Sci. Instr., 36, 326 (1959).

'Bellucci, J., and Parravano, N., Atti. Accad. Lincei, 13, 307 (1904).

\section{Toxicity of Plastics}

$X_{N}$ view of the ever-increasing use of plastics in contact with foodstuffs and like materials and the enormous amount of work done to establish their suitability for such uses, second thoughts on materials condemned without actual test might be advisable. In this respect I would like to direct attention to the results of a series of tests carried out in the laboratories of Bakelite, Limited.

We were asked to investigate the leaching-out of lead compounds from lead-stabilized polyvinyl chloride compositions in contact with a constant volume of hard and soft water. These tests were carried out by storing 6 litres of water at room temperature in tanks $18 \mathrm{in} . \times 12 \mathrm{in} . \times 5 \mathrm{in}$. deep made from the sample material by welding press-polished sheet and, after a period of 18 months contact with the water, determining the total lead content of the waters. It was shown that, with a compound stabilized with 3.77 per cent basic lead phosphite and lubricated with 0.94 per cent basic lead stearate, 0.5 part per million lead were extracted by soft water and no lead by hard water; while a compound, containing only $3 \cdot 81$ per cent dibasic lead phosphite, had none of its lead extracted by either hard or soft water. Thus it appears that only some types of lead com. pound are extracted from these compositions by water.

Although the test specimens employed and the test methods used are not those specified by the British Plastics Federation in its Toxicity Report No. 40, dated 1958, nevertheless, it is felt that the results are of considerable interest to the industry as a whole. If the total amount of lead extracted from a sample over a period of 18 months is only 0.5 part per million, then surely such a material would be satisfactory for use in pipes in contact with flowing water. In the event of water being stagnant in the pipes up to 18 months it could only produce a lead concentration of 0.5 part per million. On the other hand, formulations can be made which contain lead compounds, for example, lead phosphite, from which no lead is extracted either by hard or soft water. These results could, therefore, be considered good evidence in favour of allowing a formulation containing lead compounds to be employed in contact with water in conformity with Continental practice.

In conclusion, I suggest that polyvinyl chlorido compositions should not necessarily be condemned as being toxic just because they contain toxic substances, but should be considered in the light of the applications for which they are intended to be used.

Bakelite, Limited,

S. F. Chancellor

Redfern Road Works,

Tyseley, Birmingham 11.

\section{Separation Factors in Gas Chromatography}

IT is generally accepted among those using gas chromatography that for most separations the use of lower temperatures increases the separation factor, though, usually owing to the time taken at low temperatures, there is a limit to the use to which this effect can be put. Capillary columns can, however, be made extremely fast in their operation, and hence low temperatures can be used for separations which normally require temperatures at least $70^{\circ} \mathrm{C}$. higher.

The classically difficult separation in gas chromatography is that of meta- and para-xylene. Although nowadays this separation is relatively eommonplace owing to the use of capillary columns and selective stationary phases, an interesting separation was made in the course of routine testing at our laboratory which illustrates the effect of low-temperature operation. In this case, the stationary phase was a non- 